\title{
Racial Disparities and Barriers to Colorectal Cancer Screening in Rural Areas
}

\author{
Thad Wilkins, MD, Ralph A. Gillies, PhD, Stacie Harbuck, MS, \\ Jeonifer Garren, MS, MPH, Stephen W. Looney, PhD, and Robert R. Schade, MD
}

Introduction: This study examined barriers to colorectal cancer (CRC) screening in people living in rural areas.

Methods: We identified 2 rural counties with high rates of CRC and randomly contacted county residents by telephone using a published listing.

Results: Six hundred thirty-five of the 1839 eligible respondents (34.5\%) between the ages of 50 and 79 years living in McDuffie and Screven counties, Georgia, agreed to complete the survey. The mean age was 62.2 years (SD, \pm 7.5 years); $72.4 \%$ were women, $79.4 \%$ were white, and $19.5 \%$ were African American. African-American respondents had lower CRC screening rates $(50.4 \%)$ than whites $(63.4 \% ; \mathbf{P}=$ .009). Significantly more African Americans compared with whites reported barriers to CRC screening. Based on logistic regression analyses, having a physician recommend CRC screening had the strongest association with having a current CRC screening, regardless of race.

Conclusions: Important racial differences existed between African Americans and whites regarding the barriers to CRC screening and factors impacting current screening. However, endorsement of a small set of questionnaire items — not race - had the strongest association with being current with screening. Physician recommendation for CRC screening had the strongest association with being current with CRC screening. (J Am Board Fam Med 2012;25:308-317.)

Keywords: Colorectal Cancer, Health Care Disparities, Minority Health, Screening

Colorectal cancer (CRC) is the third most commonly diagnosed cancer in the United States. ${ }^{1}$ In 2010, an estimated 142,570 Americans were diagnosed with CRC, and approximately 51,370 died from this disease. ${ }^{1}$ All CRC screening guidelines recommend screening patients 50 years of age and older. Options for CRC screening include fecal

This article was externally peer reviewed.

Submitted 31 December 2010; revised 28 October 2011; accepted 4 November 2011.

From the Department of Family Medicine, School of Medicine (TW, RAG), Department of Biostatistics, College of Graduate Studies (JG, SWL), Department of Medicine, School of Medicine (RRS), George Health Sciences University; and the Association of American Medical Colleges (SH).

Funding: This research was made possible by an intramural grant from the Office of the Vice President for Research at the Medical College of Georgia.

Prior presentation: This work was presented at the North American Primary Care Research Group Annual Meeting, Vancouver, British Columbia, Canada, October 2007.

Conflict of interest: none declared.

Corresponding author: Thad Wilkins, 1120 Fifteenth Street, HB-4032, Augusta, GA 30912 (E-mail: twilkins@ georgiahealth.edu). occult blood tests (FOBTs), flexible sigmoidoscopy, double-contrast barium enema, computed tomography colonography, and colonoscopy. ${ }^{2-4} \mathrm{Re}-$ cent evidence suggests that improving CRC screening rates may reduce the societal burden and cost associated with the treatment of CRC by preventing some cancers and by diagnosing cancer at an earlier stage than would have been detected if screening had not occurred.

Because $80 \%$ of CRC occurs in individuals without identifiable risk factors, CRC screening targets average-risk individuals. ${ }^{2}$ Costs associated with CRC screening are an important barrier to completing screening tests. In addition, health insurance is an important determinant of completed cancer screening independent of other factors, including demographics and chronic health conditions. ${ }^{5}$ Minority populations and low socioeconomic status are 2 risk factors for low rates of CRC screening and, therefore, increased risk for CRC. ${ }^{6-8}$ African Americans have a 20\% higher incidence for CRC and $45 \%$ higher mortality from 
CRC than whites. ${ }^{9}$ The National Health Interview Survey reported that racial disparities seen with CRC screening are related to socioeconomic status, ${ }^{10}$ however, racial disparities persist despite coverage for CRC screening in a Medicare population. $^{11}$

Several studies have found consistently lower screening rates in rural versus nonrural areas. ${ }^{12-16}$ Only one study, by Greiner et $\mathrm{al}^{14}{ }^{14}$ focused on barriers to CRC screening among patients seeking care in a primary care physician's office in rural areas and found that screening in rural areas was not associated with the availability of endoscopic procedures or access to a gastroenterologist but was associated with physician discussions of CRC. In a study of 931 women aged 50 to 80 years, physician recommendation was strongly associated with a completed FOBT (odds ratio, 16.7). ${ }^{17}$ Even with a physician recommendation, adherence rates for CRC screening are low (10\% to $50 \%)$ and vary with the particular screening test recommended. ${ }^{18}$ The purpose of our study was to examine CRC screening rates and barriers to CRC screening in a rural population.

\section{Methods}

\section{Subject Population}

We initially determined CRC incidence and mortality data for Georgia counties through Oasis, which is a state-run health data mapping tool. Two rural counties, McDuffie and Screven, with higher incidence and mortality rates for CRC compared with the rest of the state were selected. McDuffie County has an estimated population of 21,917 persons; $12.1 \%$ of the population is 65 years of age or older, $52.7 \%$ are women, $60.4 \%$ are white, $38.1 \%$ are African American, and 1.4\% are other races. Screven County has an estimated population of 15,190 persons; $14.4 \%$ of the population is 65 years of age or older, $51.6 \%$ are women, $54.7 \%$ are white, $44.2 \%$ are African American, and $1.1 \%$ are other races. The median household income in McDuffie County is $\$ 33,185$ compared with $\$ 29,029$ in Screven County; both are less than the $\$ 42,679$ average in Georgia. The poverty rate is $17.8 \%$ in McDuffie County, $19.5 \%$ in Screven County, and $13.7 \%$ in Georgia. McDuffie and Screven counties have higher death rates (53.7 per 100,000 and 80.8 per 100,000 , respectively) from CRC compared with those for the state of Georgia $(44.2$ per 100,000$){ }^{19}$
Residential landline telephone listings were obtained and preselected for households with a member aged 50 to 79 years. The telephone listings were stratified by county and then arranged in random order. Of a list consisting of 4461 potential respondents, we called every 10th telephone number. If no one answered, the next number on the list was called. All calls were made between 5 and 8 PM on weekdays. Telephone calls were completed over a 6 -week period by 5 temporary employees (medical students) hired to conduct this survey. All interviewers received 2 hours of training, which included a formal didactic presentation about telephone interviewing techniques, form completion, and our structured telephone interview protocol. All interviewers practiced telephone interviews before beginning data collection. Telephone calls were monitored on a weekly basis by investigators for quality control.

Potential respondents were contacted by telephone and screened for eligibility by confirming that they were between the ages of 50 and 79 years. If someone younger than 50 answered the telephone, we asked to speak to someone who was between the ages of 50 to 79 . Once eligibility was confirmed, we presented a consent statement briefing the respondents on the nature of the questions being asked and reinforcing that participation was voluntary. No subject incentive was provided for completing the telephone survey. Institutional review board approval was obtained for this study before any respondents were contacted.

\section{Telephone Survey Instrument}

We modified previously validated survey instruments based on the Health Belief Model to assess benefits and barriers to CRC screening. ${ }^{20,21}$ The resulting survey has well-established psychometric properties for (1) benefit items for all screening tests ( $\mathrm{n}=5$ items); (2) barrier items for all screening tests ( $\mathrm{n}=6$ items); (3) barrier items specific for FOBT $(\mathrm{n}=3)$; (4) barrier items specific to flexible sigmoidoscopy and colonoscopy $(\mathrm{n}=3)$; and (5) barrier items for colonoscopy alone $(n=2)$. Perceived risk and worry regarding colon cancer were assessed with single items. ${ }^{22}$ The first part of the survey assessed demographic information including age, sex, and race. Subjects were asked about barriers to completing CRC screening tests and if they had ever completed a FOBT, flexible sigmoidoscopy, or colonoscopy. The second part of the sur- 
vey assessed perceived benefits to CRC screening, additional demographic factors (eg, marital status, education, and insurance coverage), and social influences on CRC screening.

\section{Statistical Analysis}

Descriptive analyses, $\chi^{2}$ tests, and $t$ tests were completed for demographic items. Cronbach $\alpha$ was used to measure internal consistency of barriers and benefits scales and subscales. $\chi^{2}$ or $t$ tests were completed to analyze CRC knowledge and attitudinal items to examine differences between respondents who were current or not current with CRC screening. Perceived barriers and benefits to each screening test and overall CRC screening were analyzed using $\chi^{2}$ tests to compare groups defined by current screening status, race, and education level. Step-wise variable selection, backward elimination, and best subsets logistic regression (LR) were used to identify potential LR models for further consideration. Diagnostic criteria for LR models (Hosmer-Lemeshow test, generalized $\mathrm{R}^{2}$, etc.) were used to assess the goodness of fit of the various models that were considered. Each variable selection method was applied to several collections of potential explanatory variables (demographic and medical characteristics only, demographic and medical characteristics plus benefits scale and barrier scale scores, demographic and medical characteristics plus benefits and barriers scale items, etc.) and the best-fitting LR model from each collection was retained, provided it was satisfactory according to the LR diagnostic criteria. As is typically done, the variable selection procedures were performed using only those subjects who had complete data for all explanatory variables being considered for inclusion in the particular LR model. Once the variable selection process was completed, the LR model was estimated using all subjects with complete data for the selected explanatory variables. The LR model that performed best overall in terms of the statistical criteria and was considered to be the most useful model clinically was selected as the "final" retained LR model. Receiver operating characteristic (ROC) curve analysis was used to determine the final model's ability to accurately discriminate between patients who were current with their CRC screening and those who were not. Data were analyzed using SPSS (version 16.0, IBM, Chicago, IL) and SAS (version 9.2, SAS Institute Inc., Cary, NC) software.

\section{Results}

\section{Respondent Demographics}

From a list of 4461 potential respondents, 1839 eligible telephone numbers in 2 rural Georgian counties were called for this study, and 635 respondents (34.5\% acceptance rate) agreed to participate (see Figure 1). The mean age of respondents was 62.2 years (standard deviation, \pm 7.5 ), and $72.4 \%$ were women. The majority of respondents $(79.4 \%)$ were white, and $19.5 \%$ were African American. Most respondents (64.2\%) were married or a member of an unmarried couple. Forty percent of respondents had attained a high school diploma or GED certificate, and $40.8 \%$ completed college or had some college education.

Three hundred eighty-two respondents (60.2\%) had current CRC screening defined as a FOBT within 1 year, a flexible sigmoidoscopy within 5 years, or a colonoscopy within 10 years. In analyses, "current with CRC screening" indicates the respondent has a current CRC screening status with at least one of the CRC screening types; this is a categorical variable (yes/no). Slightly fewer respondents in McDuffie County were current with CRC screening than in Screven County $(57.2 \%$ vs $65.6 \%$, respectively; $P=.036)$. Older respondents (70-79 years of age) were more likely than younger

\section{Figure 1. Subject flow diagram.}

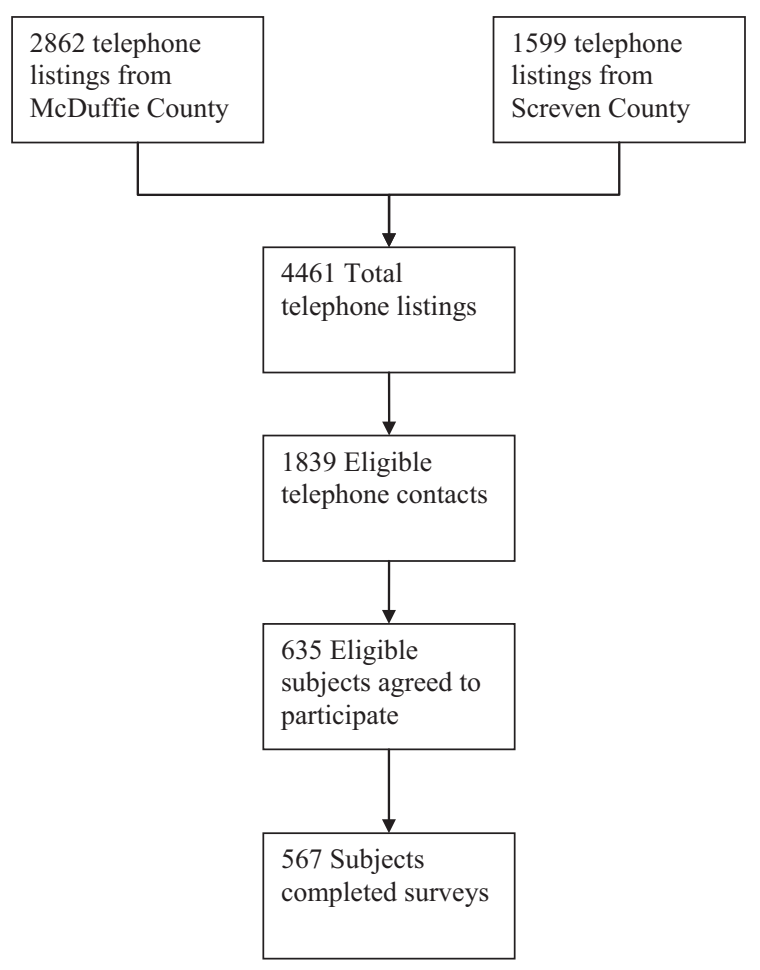


respondents (50- 59 years of age) to have current screenings $(P=.002)$. There were no differences in screening rates between male and female respondents $(P=.779)$. Other factors associated with higher current screening rates included having insurance $(P<.001)$, having a personal doctor $(P<.001)$, personally knowing someone with CRC $(P=.003)$, having graduated from college $(P=.005)$, having an immediate family member with CRC $(P=.006)$, and having a higher perceived risk of developing CRC $(P=.015)$. See Table 1 for a summary of respondent characteristics and CRC screening status.

A higher percentage of whites reported having current CRC screening compared with African

Table 1. Comparison of Screening Status By Respondent Demographic Characteristics

\begin{tabular}{|c|c|c|c|}
\hline & $\begin{array}{l}\text { Not Current With } \\
\text { CRC Screening }\end{array}$ & $\begin{array}{l}\text { Current With } \\
\text { CRC Screening }\end{array}$ & $P$ \\
\hline \multicolumn{4}{|l|}{ Age, years $(n=622)$} \\
\hline $50-59$ & $121(46.4)$ & $140(53.6)$ & \multirow[t]{3}{*}{.002} \\
\hline $60-69$ & $92(38.3)$ & $148(61.7)$ & \\
\hline $70-79$ & $33(27.3)$ & $88(72.7)$ & \\
\hline \multicolumn{4}{|l|}{$\operatorname{Sex}(n=623)$} \\
\hline Female & $178(39.5)$ & $273(60.5)$ & \multirow[t]{2}{*}{.779} \\
\hline Male & $70(40.7)$ & $102(59.3)$ & \\
\hline \multicolumn{4}{|l|}{$\operatorname{Race}^{*}(\mathrm{n}=615)$} \\
\hline African American & $60(49.6)$ & $61(50.4)$ & \multirow[t]{2}{*}{.009} \\
\hline White & $181(36.6)$ & $313(63.4)$ & \\
\hline \multicolumn{4}{|l|}{ Marital status $(\mathrm{n}=562)$} \\
\hline Not married & $83(41.3)$ & $118(58.7)$ & \multirow[t]{2}{*}{.171} \\
\hline Married or member of unmarried couple & $128(35.5)$ & $233(64.5)$ & \\
\hline \multicolumn{4}{|l|}{ Education $(\mathrm{n}=562)$} \\
\hline Some high school or less & $47(43.9)$ & $60(56.1)$ & \multirow[t]{3}{*}{.005} \\
\hline High school graduate, GED, or some college & $135(40.2)$ & $201(59.8)$ & \\
\hline College graduate & $30(25.2)$ & $89(74.8)$ & \\
\hline \multicolumn{4}{|l|}{ Insurance status $(\mathrm{n}=563)$} \\
\hline No health care insurance coverage & $47(74.6)$ & $16(25.4)$ & \multirow[t]{2}{*}{$<.0001$} \\
\hline Health care insurance coverage & $167(33.4)$ & $333(66.6)$ & \\
\hline \multicolumn{4}{|l|}{ Personal doctor $(\mathrm{n}=562)$} \\
\hline Does not have personal doctor & $34(85.0)$ & $6(15.0)$ & \multirow[t]{2}{*}{$<.0001$} \\
\hline Does have personal doctor & $179(34.3)$ & $343(65.7)$ & \\
\hline \multicolumn{4}{|l|}{ County $(\mathrm{n}=627)$} \\
\hline McDuffie & $164(42.8)$ & $219(57.2)$ & \multirow[t]{2}{*}{.036} \\
\hline Screven & $84(34.4)$ & $160(65.6)$ & \\
\hline \multicolumn{4}{|l|}{ Knows family member with CRC $(\mathrm{n}=561)$} \\
\hline Family member without CRC & $190(40.4)$ & $280(59.6)$ & \multirow[t]{2}{*}{.006} \\
\hline Family member with CRC & $23(25.3)$ & $68(74.7)$ & \\
\hline \multicolumn{4}{|l|}{ Knows person with CRC $(\mathrm{n}=558)$} \\
\hline No known person with CRC & $130(43.2)$ & $171(56.8)$ & \multirow[t]{2}{*}{.003} \\
\hline Knows person with CRC & $80(31.1)$ & $177(68.9)$ & \\
\hline \multicolumn{4}{|l|}{ Worried about CRC $(\mathrm{n}=558)$} \\
\hline No worry about CRC & $177(37.8)$ & $291(62.2)$ & \multirow[t]{2}{*}{.557} \\
\hline Worries about CRC & $37(41.1)$ & $53(58.9)$ & \\
\hline \multicolumn{4}{|l|}{ Perceived risk of CRC compared to others $(n=365)$} \\
\hline Lower than men or women same age & $30(33.3)$ & $60(66.7)$ & \multirow[t]{3}{*}{.015} \\
\hline Same as men or women same age & $83(44.4)$ & $104(55.6)$ & \\
\hline Higher than men or women same age & $24(27.3)$ & $64(72.7)$ & \\
\hline
\end{tabular}

Values shown as $\mathrm{n}(\%) \cdot \chi^{2}$ analyses were conducted for the above factors.

*Other races not included in analyses because of small sample size $(n=7)$.

CRC, colorectal cancer; GED, general education development certificate. 
Americans $(63.4 \%$ vs $50.4 \%$, respectively; $P=$ .009). Additional racial demographics may provide context for the significant screening status by race finding. A greater proportion of African Americans had less than a high school education than did whites $(43.9 \%$ vs $13.1 \%$, respectively; $P<.001$ ), and a larger percentage of African Americans were uninsured compared with whites $(16.3 \%$ vs $10.2 \%$, respectively; $P=.08$ ). A slightly higher percentage of whites were in the 70- to 79-year-old age category than African Americans (20.8 vs $13.7 \%$, respectively; $P=.14)$. Of the respondents with current screening ( $\mathrm{n}=382), 44.0 \%$ had a current FOBT, $38.7 \%$ had a current flexible sigmoidoscopy, and $77.0 \%$ a current colonoscopy (sum is $>100 \%$ because some respondents have had more than 1 test). Table 2 shows a summary of currently screened respondents by test type, race, sex, and age. There were no racial disparities between whites and African Americans for current screening with FOBT $(26.7 \%$ vs $25.6 ; P=.81)$ or flexible sigmoidoscopy (25.3\% vs $19.0 \% ; P=.15)$, but whites were far more likely than African Americans to have a current colonoscopy screening $(51.0 \%$ vs $29.8 \% ; P<.001)$.

\section{CRC Screening Among Respondents}

The majority of respondents had heard of the 3 common screening tests; colonoscopy was the most recognized test $(90.9 \%)$, followed by FOBT (78.9\%), and then flexible sigmoidoscopy (61.4\%). Sixty-nine percent of subjects had completed a
FOBT; $54.4 \%$ had completed a flexible sigmoidoscopy, and $56.4 \%$ had completed a colonoscopy.

\section{Perceived Barriers and Benefits to CRC Screening}

The 17 items assessing respondents' perceived barriers to specific CRC screening tests and CRC screening in general yielded a relatively high Cronbach $\alpha$ coefficient (0.81). Removal of any of the items did not significantly improve reliability of the items. The 5 colonoscopy items had the highest subscale Cronbach $\alpha$ (0.74), followed by the 3 FOBT items (0.45), the 3 flexible sigmoidoscopy items (0.44), and the 6 general barriers to CRC screening (0.43). The 5 items assessing perceived benefits for CRC screenings yielded a strong Cronbach $\alpha$ coefficient $(0.81)$, with no items improving reliability if removed.

African-American respondents indicated greater agreement with 2 general CRC barriers than did white respondents (insufficient time with a physician, $P=.018$, and high screening cost, $P=.005$ ), whereas white respondents reported greater embarrassment with screenings $(P=.005)$. African Americans indicated greater uncertainty with how to complete FOBT $(P<.001)$ and greater concern about privacy to collect samples $(P<.001)$. For flexible sigmoidoscopy, African Americans indicated more concern about bowel preparation $(P<$ $.001)$ and anxiety about what was actually done during the procedure $(P=.050)$. For colonoscopy, African Americans rated all 5 of the barrier items (anxious because they did not understand the pro-

Table 2. Current Screening Status by Fecal Occult Blood Test, Flexible Sigmoidoscopy, or Colonoscopy, By Demographics

\begin{tabular}{|c|c|c|c|c|c|c|}
\hline & FOBT $^{*}$ & $P$ & Flexible Sigmoidoscopy* & $P$ & Colonoscopy* & $P$ \\
\hline \multicolumn{7}{|l|}{ Sex } \\
\hline Male & $43(25.0)$ & .53 & $47(27.3)$ & .16 & $82(47.7)$ & .66 \\
\hline Female & $124(27.5)$ & & $99(22.0)$ & & $206(45.7)$ & \\
\hline \multicolumn{7}{|l|}{ Race $^{\dagger}$} \\
\hline White & $132(26.7)$ & .81 & $125(25.3)$ & .15 & $252(51.0)$ & $<.001$ \\
\hline African American & $31(25.6)$ & & $23(19.0)$ & & $36(29.8)$ & \\
\hline \multicolumn{7}{|l|}{ Age (years) } \\
\hline $50-59$ & $57(21.8)$ & .003 & $53(20.3)$ & .13 & $109(41.8)$ & $<.001$ \\
\hline $60-69$ & $81(33.8)$ & & $57(23.8)$ & & $106(44.2)$ & \\
\hline $70-79$ & $25(20.7)$ & & $36(29.8)$ & & $75(62.0)$ & \\
\hline
\end{tabular}

Values provided as $\mathrm{n}(\%)$.

*Percentages for specific tests do not sum to $100 \%$ because some respondents had more than one current screening test.

†Other races were not included in analyses because of small sample size $(\mathrm{n}=7)$.

FOBT, fecal occult blood test. 
cedure, afraid of complication, preparation, transportation, and anticipated pain with colonoscopy) significantly higher than whites $(P=.003)$. For perceived benefits, whites agreed more than African Americans with 2 benefit items: finding CRC early decreases chances from dying from it $(P=$ $.002)$ and screening decreases their worry $(P=$ .004). Respondents who had a higher educational level consistently reported fewer barriers than respondents with lower educational levels. Table 3 shows a summary of perceived barriers and benefits by current screening status, race, and education.

Respondents who had a current screening on at least one of the 3 CRC tests consistently endorsed less agreement with barriers to completing a CRC screening and greater agreement with perceived benefits of screening than respondents not current with screening. Most of the barrier items were significant at $P \leq .001$ except 2 items that were significant to a lesser degree or not significant: embarrassment with CRC screening and collecting FOBT is unpleasant $(P=.033$ and not significant, respectively). For perceived benefits of screening, respondents with current screening consistently endorsed benefits more strongly than respondents who were not current with screening.

Odds ratios were used to examine the association between explanatory variables (demographic and medical characteristics, social influences and support items, barriers items, benefits items, total barriers and benefits scale scores, etc.) and dichotomous outcome (current CRC screening vs not current). All explanatory variables that were significant at the 0.05 level individually were entered into a variable selection process for LR analysis, similar to that described by Hosmer and Lemeshow, ${ }^{23}$ to identify the most parsimonious subset of explanatory variables.

The variable selection process retained 4 of the explanatory variables in the final LR model: 2 barrier items ("My physician has spent enough time discussing colorectal cancer and the screening tests" and "You do not need to do a screening test for colorectal cancer because you have no problems"), one benefit item ("A screening test will decrease your chances of dying from colorectal cancer"), and one social influences and support item ("Has anyone in your immediate family had colorectal cancer?"). The parameters of the fitted model, along with the estimated odds ratio for each retained explanatory variable, are given in Table 4.
This model was based on a sample size of $n=477$ out of the original sample size of 635 . The Hosmer-Lemeshow test indicated adequate goodnessof-fit of this model $(P=.540)$ and the generalized $\mathrm{R}^{2}$ value of 0.250 was the best among the 5 candidates for best model. The area under the ROC curve for this LR model was 0.76 .

To examine how well the final LR model could be used as a screening tool to identify patients who are not current with their CRC screening and thus are indicated for additional intervention to encourage them to become current, we developed a "risk score" for each participant in our study based on their estimated probability of not being current with CRC screening, calculated using the estimated model coefficients presented in Table 4. Any patient whose risk score is 0.380 or more would be classified as likely to be not current with CRC screening and hence in need of intervention. This cutoff point yielded an estimated sensitivity of $68 \%$. Any patient whose risk score was less than 0.380 would be classified as likely to be current with CRC screening and not in need of intervention, yielding an estimated specificity of $74 \%$. Using the 0.380 cutoff point, the estimated total percent correctly classified was $72 \%$.

\section{Discussion}

Within our study of 2 rural Georgia counties (McDuffie and Screven), we had an average completion rate $(34.5 \%)$ of our telephone survey. Sixty percent of respondents reported they had completed CRC screening. This relatively high screening rate was unexpected in these 2 rural counties, but callers who had been screened previously may have been more willing to complete our telephone survey, thereby introducing selection bias into our sample. Older persons within the age range of our sample were more likely to have completed CRC screening compared with younger persons. This may reflect a greater frequency of physician visits or that older patients had Medicare and less out-of-pocket medical expenses compared with younger patients who were without insurance, were underinsured, or had high copayments.

We found significant racial differences in overall screening rates in whites versus African Americans and in the types of screening tests completed. Whites reported current CRC screening more often and were more likely to have completed a 


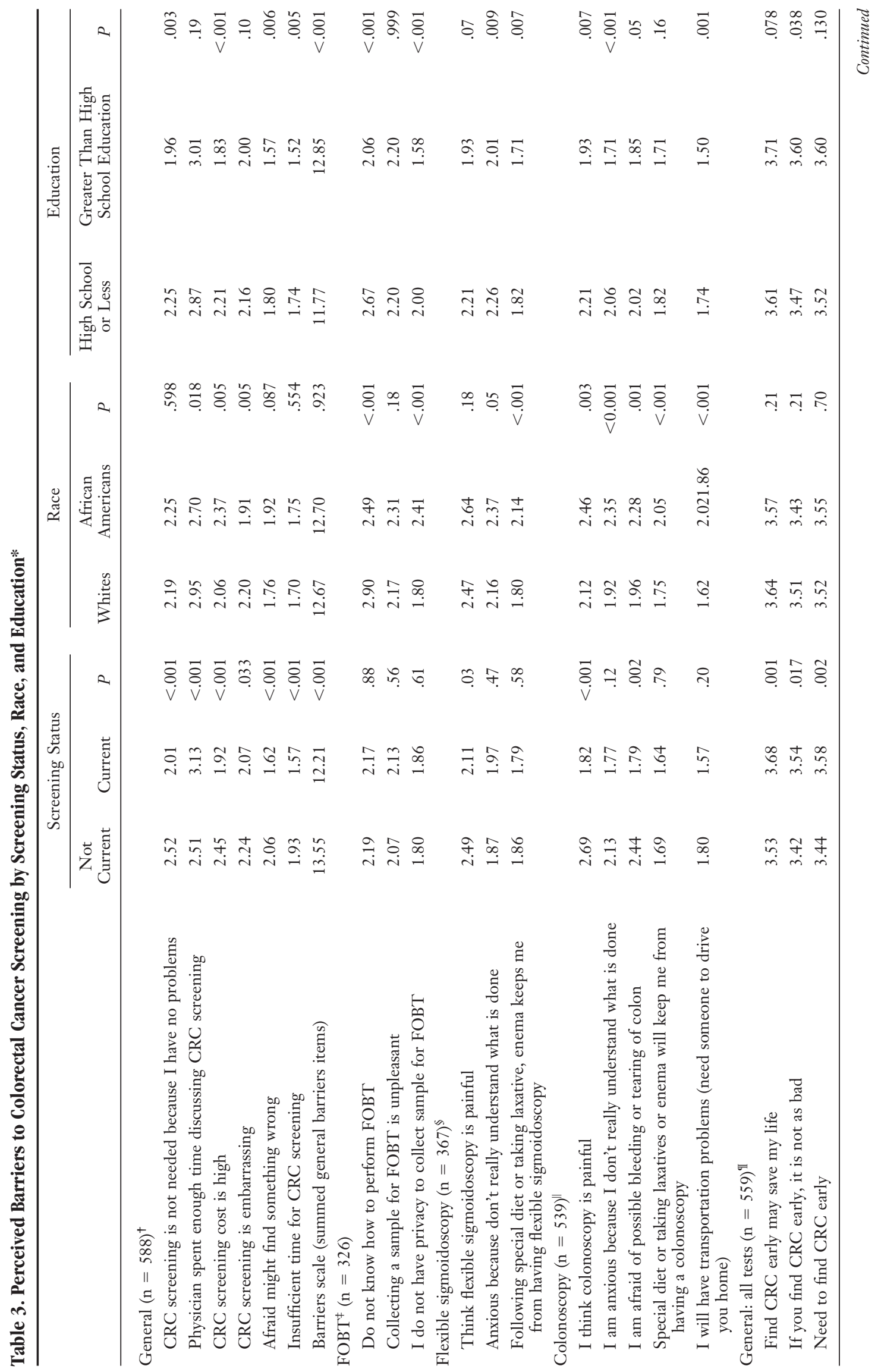




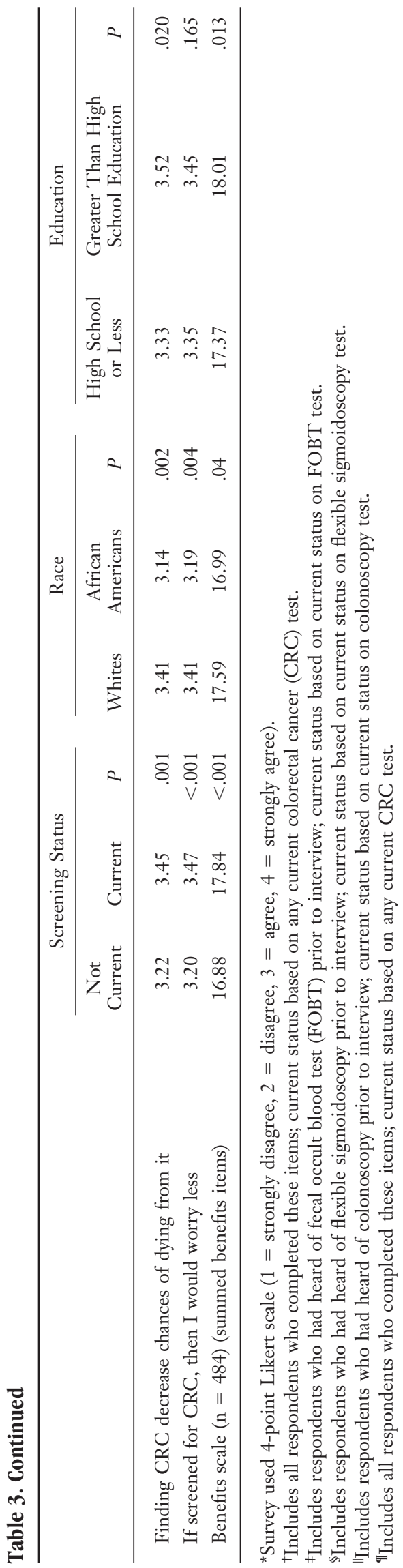

colonoscopy than African Americans, whereas African Americans were more likely to have completed FOBT. We hypothesize that these differences may be accounted for by socioeconomic status, which would be supported by previous CRC literature. In addition, physician recommendation is more important for African Americans than for whites, which confirms that a physician recommendation is an important factor for persons completing CRC screening. ${ }^{14,17,18}$ Compared with white respondents, African Americans also were more likely to report the following barriers to screening: perceived barriers of physician time, screening cost being high, and screening being embarrassing.

In general, the 2 rural counties that we studied have a higher poverty rate, lower educational level, more limited access to health professionals, and less coverage by health insurance compared with other counties in Georgia. Several studies have looked at the barriers to and potential benefits of reaching out to lower socioeconomic status populations for CRC screening. A recent systematic review reported that lower socioeconomic status was correlated with a higher incidence and mortality rate from CRC within the United States and Canada. ${ }^{8}$ In a qualitative study, lower socioeconomic status respondents expressed that a major barrier to CRC screening was the quality of care (eg, the perceived lack of screening being offered and the follow-up of test results). ${ }^{24}$ In addition, a study of 5978 patients found significant racial and socioeconomic status differences in cancer screening discussions, including those for CRC screening. ${ }^{25}$

In an exploratory, follow-up analysis of the LR results, the ROC curve analysis completed in this study suggests a potentially useful method for assessing and addressing CRC screening status with patients. Patients who endorse "insufficient physician time," "no problems related to CRC," and "immediate family had CRC" and who fail to endorse "screening test decreases chances of dying from CRC" are less likely to have current CRC screening. Using a cutoff point of 0.380 for the "risk score" based on a patient's estimated probability of not being current with CRC screening yielded the best balance between sensitivity (probability of correctly identifying those not current with their CRC screening) and specificity (probability of correctly identifying those who are current with their CRC screening). These results are encouraging and suggest that this risk score should be 
Table 4. Selected Explanatory Variables for Current Colorectal Cancer Screening

\begin{tabular}{|c|c|c|c|c|c|c|}
\hline Explanatory Variable & Estimated Coefficient & Standard Error & $x^{2}$ & $P$ & Odds Ratio & $95 \% \mathrm{CI}$ \\
\hline \multicolumn{7}{|l|}{ Barrier items } \\
\hline $\begin{array}{l}\text { My physician has spent enough time } \\
\text { discussing colorectal cancer and the } \\
\text { screening tests. }\end{array}$ & 0.80 & 0.12 & 46.81 & $<.001$ & 2.22 & $1.76-2.78$ \\
\hline $\begin{array}{l}\text { You do not need to do a screening test for } \\
\text { colorectal cancer because you have no } \\
\text { problems. }\end{array}$ & -0.58 & 0.12 & 24.92 & $<.001$ & 0.56 & $0.44-0.70$ \\
\hline \multicolumn{7}{|l|}{ Benefit item } \\
\hline $\begin{array}{l}\text { A screening test will decrease your chances of } \\
\text { dying from colorectal cancer. }\end{array}$ & 0.35 & 0.14 & 6.26 & .012 & 1.42 & $1.08-1.87$ \\
\hline \multicolumn{7}{|l|}{ Social influences and support question } \\
\hline $\begin{array}{l}\text { Has anyone in your immediate family had } \\
\text { colorectal cancer? }\end{array}$ & 0.58 & 0.29 & 3.86 & .049 & 1.79 & $1.00-3.18$ \\
\hline
\end{tabular}

CI, confidence interval

evaluated more thoroughly in a future study as a possible screening tool for inadequate CRC screening in a general population. A potential by-product of this line of research would be a computer-based tool that would help physicians identify which of their patients who are not CRC screening current likely will need additional counseling to complete CRC screening.

\section{Limitations}

One limitation of our study is that we relied on self-reported survey data. We made no attempt to verify the accuracy of responses. We did not track information about respondents who did not complete the telephone survey. We did not assess health literacy, the last time the respondent was seen by a health care provider, or patients' proximity to a health care provider. Our sample included more women and whites, which may have introduced selection bias into our sample. Our survey asked about marital status at the time the survey was taken and not when the CRC screening test was completed.

\section{Conclusions}

Although the rate of respondents reporting that they were current with CRC screening was relatively high in our study, racial disparities existed in 2 rural counties in Georgia. African Americans are screened less often than whites and, when screened, are more likely to be screened with FOBT rather than flexible sigmoidoscopy or colonoscopy. Our study confirms that the most important factor for CRC screening is a recommendation from a per- sonal physician, and this finding is more important among African-American patients.

We thank Stan Sulkowski, BS, for his assistance as the study coordinator.

\section{References}

1. Jemal A, Siegel R, Xu J, Ward E. Cancer statistics, 2010. CA Cancer J Clin 2010;60(5):277-300.

2. Winawer S, Fletcher R, Rex D, et al. Colorectal cancer screening and surveillance: clinical guidelines and rationale-Update based on new evidence. Gastroenterology 2003;124(2):544-60.

3. Smith RA, Cokkinides V, Eyre HJ. American Cancer Society guidelines for the early detection of cancer, 2005. CA Cancer J Clin 2005;55(1):31-44; quiz $55-6$.

4. Pignone M, Rich M, Teutsch SM, Berg AO, Lohr KN. Screening for colorectal cancer in adults at average risk: a summary of the evidence for the U.S. Preventive Services Task Force. Ann Intern Med 2002;137(2):132-41.

5. Hsia J, Kemper E, Kiefe C, et al. The importance of health insurance as a determinant of cancer screening: evidence from the Women's Health Initiative. Prev Med 2000;31(3):261-70.

6. Shokar NK, Carlson CA, Weller SC. Factors associated with racial/ethnic differences in colorectal cancer screening. J Am Board Fam Med 2008;21(5): $414-26$.

7. Frederiksen BL, Osler M, Harling H, Ladelund S, Jorgensen T. Do patient characteristics, disease, or treatment explain social inequality in survival from colorectal cancer? Soc Sci Med 2009;69(7):1107-15.

8. Aarts MJ, Lemmens VE, Louwman MW, Kunst AE, Coebergh JW. Socioeconomic status and changing inequalities in colorectal cancer? A review of the 
associations with risk, treatment and outcome. Eur J Cancer 2010;46(15):2681-95.

9. American Cancer Society. Colorectal cancer facts and figures 2008-2010. Atlanta: American Cancer Society; 2008.

10. Lees KA, Wortley PM, Coughlin SS. Comparison of racial/ethnic disparities in adult immunization and cancer screening. Am J Prev Med 2005;29(5):404-11.

11. Ananthakrishnan AN, Schellhase KG, Sparapani RA, Laud PW, Neuner JM. Disparities in colon cancer screening in the Medicare population. Arch Intern Med 2007;167(3):258-64.

12. Casey MM, Thiede Call K, Klingner JM. Are rural residents less likely to obtain recommended preventive healthcare services? Am J Prev Med 2001;21(3):182-8.

13. Coughlin SS, Thompson TD. Colorectal cancer screening practices among men and women in rural and nonrural areas of the United States, 1999. J Rural Health 2004;20(2):118-24.

14. Greiner KA, Engelman KK, Hall MA, Ellerbeck EF. Barriers to colorectal cancer screening in rural primary care. Prev Med 2004;38(3):269-75.

15. Muldoon JT, Schootman M, Morton RF. Utilization of cancer early detection services among farm and rural nonfarm adults in Iowa. J Rural Health 1996; 12(4 Suppl):321-31.

16. Thompson B, Coronado G, Neuhouser M, Chen L. Colorectal carcinoma screening among Hispanics and non-Hispanic whites in a rural setting. Cancer 2005;103(12):2491-8.

17. Mandelson MT, Curry SJ, Anderson LA, et al. Colorectal cancer screening participation by older women. Am J Prev Med 2000;19(3):149-54.
18. Vernon SW. Participation in colorectal cancer screening: a review. J Natl Cancer Inst 1997;89(19): $1406-22$.

19. Office of Health Indicators for Planning, Georgia Department of Public Health. Online Analytical Statistical Information System (OASIS). 13 March 2012. Available from: http://oasis.state.ga.us/. Accessed 4 December 2008.

20. Rawl S, Champion V, Menon U, Loehrer P, Vance G, Skinner CS. Validation of scales to measures beliefs of and barriers to colorectal cancer screening. J Psycholsoc Oncol 2001;19:47-63.

21. Janz NK, Wren PA, Schottenfeld D, Guire KE. Colorectal cancer screening attitudes and behavior: a population-based study. Prev Med 2003;37(6 Pt 1): 627-34.

22. Wardle J, Williamson S, McCaffery K, et al. Increasing attendance at colorectal cancer screening: testing the efficacy of a mailed, psychoeducational intervention in a community sample of older adults. Health Psychol 2003;22(1):99-105.

23. Hosmer DW, Lemeshow S. Applied logistic regression. Second ed. New York: John Wiley \& Sons; 2000.

24. Holmes-Rovner M, Williams GA, Hoppough S, Quillan L, Butler R, Given CW. Colorectal cancer screening barriers in persons with low income. Cancer Pract 2002;10(5):240-7.

25. Bao Y, Fox SA, Escarce JJ. Socioeconomic and racial/ethnic differences in the discussion of cancer screening: "between-" versus "within-" physician differences. Health Serv Res 2007;42(3 Pt 1):950-70. 